\title{
Low Cost Automation for Manufacturing of Conveyor Chain Bushes
}

\author{
Sumit Patil ${ }^{1,}$ Atul Patil ${ }^{2}$ Prashant Gunjawate ${ }^{3}$ \& Ganesh Rakate ${ }^{4}$ \\ ${ }^{I}$ Sumit Patil_Assistant professor, Annasaheb Dange College of Engineering \& Technology, Ashta, India \\ ${ }^{2}$ Atul Patil_Assistant professor, Rajarambapu Institute of Technology, Rajaramnagar, Sakharale, India \\ ${ }^{3}$ Prashant Gunjawate_Assistant professor, Rajarambapu Institute of Technology, Rajaramnagar Sakharale, \\ India \\ ${ }^{4}$ Ganesh Rakate_Assistant professor, Annasaheb Dange College of Engineering \& Technology, Ashta, India
}

\begin{abstract}
Low Cost Automation (popularly known as LCA) is the introduction of simple pneumatic, hydraulic, mechanical and electrical devices into the existing production process or/and machinery, with a view to improving their productivity. These would also enable the operation of these equipments by even semi-skilled and unskilled labour, with a little training. This will involve the use of standardised parts and devices to mechanise or automate machines, processes and systems. LCA is a technology that creates some degree of automation around the existing equipment, tools, methods, people, etc, using mostly standard components available in the market with low investment so that the payback period is short. The current financial crisis faced all over the world has posed tremendous challenges on the manufacturing organisations. Even at low volumes, and large variety, they have to be competitive with minimum investment. Low-cost automation can play an important role in this situation.

This paper discusses the case study of low cost automation for manufacturing of conveyor chain bushes and comparison of productivity of component using conventional horizontal milling machine. In this case study, the Low Cost Automation technique is used for manufacturing of conveyor chain bushes which requires two flat milling operations at both ends. In this paper the following studies are carried out 1 . Reduction in cycle time due to automation, 2. Increase in productivity both qualitative and quantitative, 3. Less human intervention, indirectly reduction in operator fatigue, 4. Less rejection due to automatic controls and 5. Increase the profit of company with economic justification of payback period.
\end{abstract}

Keywords: Design and Development, Low cost automation, Productivity

\section{INTRODUCTION}

The component for which low cost automation carried out is a bush for chain conveyors. These chain conveyors are used in sugar industries and other process industries for material handling purposes. Dimensions of bush vary according to design of conveyors but basic geometry of

all bushes remain same. Figure 1 shows the basic geometry of bush.

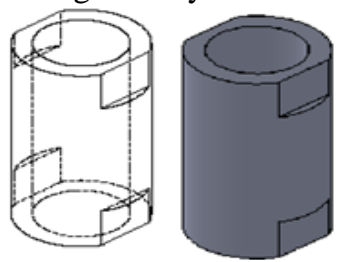

Figure 1: Basic geometry of bush

Four milling operations (two at both ends which are diametrically opposite to each other) are required to be carried out on work piece to manufacture bush.

In earlier process of manufacturing the bushes were machined by using conventional horizontal milling machine with appropriate fixture. By using conventional process only two side milling operations were performed on each bush at a time and all job setting and machining activities carried out manually. To rectify these drawbacks low cost automation project is designed and developed by following USA approach of automation and process improvement. According to this approach existing manufacturing process is understood, simplified and automated. New concept of automation is developed with focus on specialization of operation, simultaneous operation and increased flexibility strategies of automation at minimum investment. 


\section{SETUP DETAILS}

The new developed system consists of use gang milling system. Four side milling operations which require two setups for each job should possible to manufacture in a single setup. Machine includes automatic clamping, de-clamping and feed providing system. Machine is capable to manufacture all types of bushes with minor changes in tool setting and fixture setup. Design calculations of various parts are made by following engineering principles and technical information. Parts are designed to meet functional requirements and also DFM and DFMA principles keeping in mind. The final outcome of the design process consists of description of system in the form of drawings of assemblies and individual components. Various two-dimensional (2-D) and three dimensional (3-D) geometric drawings are prepared by using Solid Works CAD software.

\subsection{MECHANISM OF SPM}

Mechanism of new developed automation system consists of -

1. Two vertical spindle milling heads with two cutters on each for performing four side milling operations simultaneously in single setup.

2. Lead screw mechanism for providing feed to milling head column.

3. Hydraulic mechanism for providing automatic feed to work table and for automatic clamping and declamping of work holding fixture.

4. Mechatronics means for controlling and synchronizing various hydraulic cycles, limit switches signal system and manufacturing operations.

Subassemblies of automation system are discussed further along with three dimensional views prepared in Solid Works CAD software.

\subsection{HEADSTOCK ASSEMBLY}

Exploded three dimensional view of headstock assembly is shown figure 2. This assembly is designed to rotate the milling cutters and hence providing cutting force for performing milling operation on work piece.

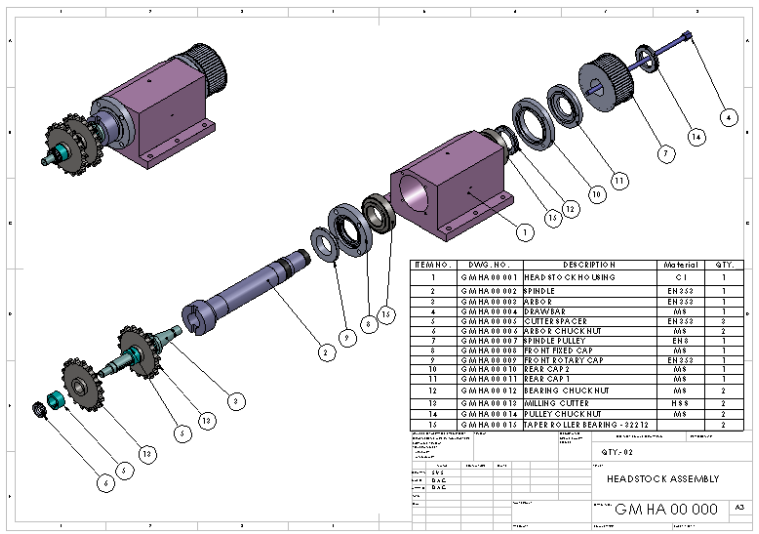

Figure 2: Headstock assembly

Assembly consists of cast iron head stock housing with honing bore for interference fitment of cup of taper roller bearings. Main part of this subassembly is spindle made from case hardened EN 353 material. This spindle is secured in headstock housing by using two taper roller bearings in back to back arrangement. Bearing selection is done by following standard bearing selection procedure and referring SKF bearing selection catalogue. Diameter of spindle is calculated by following standard shaft design process and checked by static structural analysis using finite element software - Ansys. Bearing sizes are provided at two positions on spindle by cylindrical grinding process. Spindle consists of ISO 40 taper grinded hole for securing arbor. Arbor is also made from case hardened EN 353 material with taper portion at one end. At one end of arbor tapping is provided so it can lock in spindle taper hole by screwing draw bar from one end of subassembly. Arbor is positively locked to spindle by fitting square pins in two slots provided at front ends of spindle and arbor. Key way is provided on arbor for mounting milling cutters. Distance between cutters is adjusted by placing cutter spacer of suitable length between cutters according to dimensions of work piece to be machined and locked in position by tightening chuck nuts and lock washer. Timing belt pulley is push fitted and keyed to spindle. Front fixed cap is fitted to headstock housing. Front rotary cap inserted in front fixed cap. Rear cap 2 is fitted to headstock housing. Rear cap 1 is fitted to Rear cap 2. Bearings are preloaded by bearing chuck nuts and locked in position by lock washer. Drive to timing pulley is provided by three horse power squirrel cage induction motor through timing belt. Design and selection of timing belt and timing pulley is done by referring GATES 
rubber company catalogue. Design and selection of electric motor is done by following engineering principles, mathematic calculations and referring manufactures catalogue published by Hindustan Electrical Motors.

\subsection{DOVETAIL SLIDE ASSEMBLY}

Exploded three dimensional view of dovetail slide assembly is shown in figure 3. This assembly is designed to provide depth of cut while performing milling operation. Lead screw mechanism is used to convert rotary motion in to linear motion.

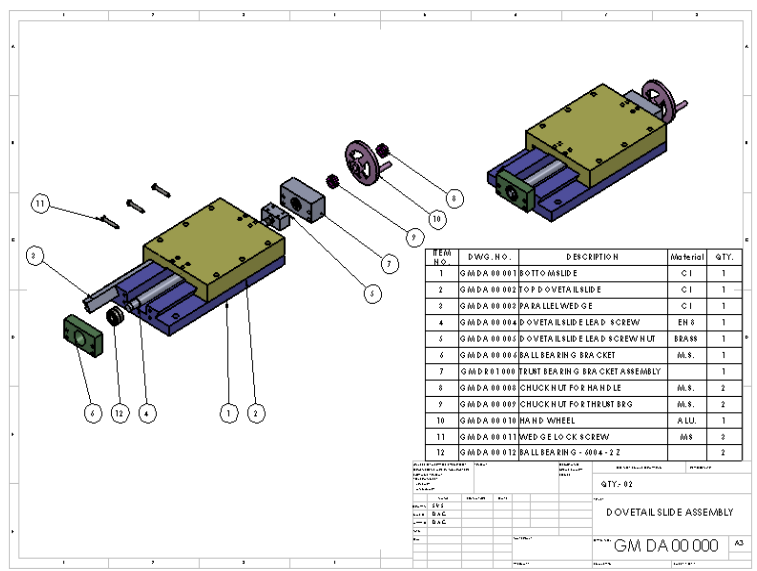

Figure 3: Dovetail slide assembly

Assembly consists of cast iron bottom slide on which top dovetail slide is mounted. Mating faces of bottom slide and top dovetail slide are grinded and scraped so that there should be smooth relative motion in between them. Dimensional limits and geometrical tolerances are provided such that both slides should align properly and to achieve accurate movement of top dovetail slide while working of assembly. Parallel wedge is placed in between two slides to adjust clearance between them. Lead screw is square threaded and secured in position by fitting in bearing block assemblies at both ends. Ball bearing bracket is provided at one end of lead screw to fit ball bearings to take radial load. At other end thrust bearing assembly is provided to fit thrust bearings and to take thrust load. Brass bush is placed between two thrust bearings so that there should be minimum wear of lead screw as brass is possessing good bearing property. Lead screw is assembled with top dovetail slide by using dovetail slide lead screw nut which is also made up of brass metal. Hand wheel is keyed to lead screw end.

When hand wheel is rotated there is rotary motion of lead screw. This rotary motion is converted into linear motion of top dovetail slide by means of lead screw nut. As head stock assembly is fitted on column which is fitted on top dovetail slide; linear movement of top dovetail slide provides depth of cut for performing milling operation on work piece when hand wheel is rotated.

\subsection{SLIDE ASSEMBLY}

Exploded three dimensional view of slide assembly is shown in figure 4. This assembly is designed to provide feed while performing milling operation.

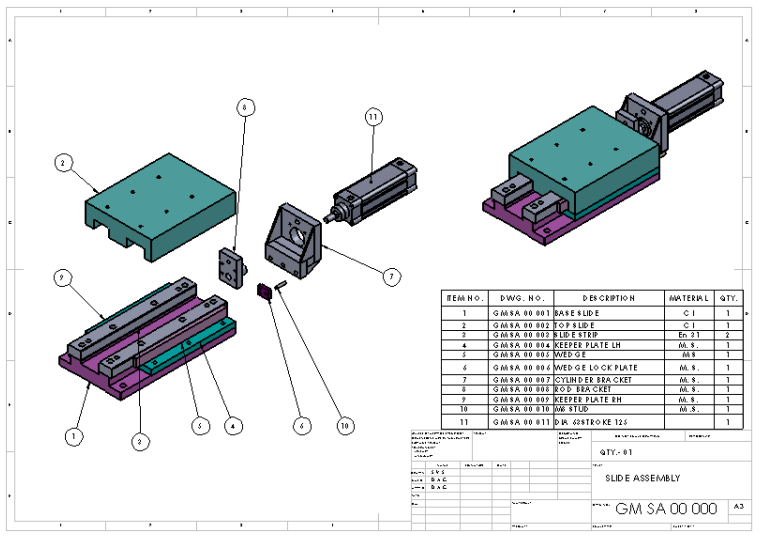

Figure 4: Slide assembly 
This assembly consists of cast iron base slide with grinded faces on which two slide strips are fitted. Slide strips are made up of through harden EN 31 material. On slide strips cast iron top slide is mounted. Mating faces of top slide with slide strips are grinded and scraped so that there should be smooth relative motion in between them. Dimensional limits and geometrical tolerances are provided to top slide such that it should align properly and to achieve accurate movement of top slide while working of assembly. Keeper plates are fitted to top slide to lock it in position. Adjustable wedge is placed in between base slide and top slide. Cylinder bracket is fitted to one side of base slide to mount hydraulic cylinder. Rod of this hydraulic cylinder is locked with top slide by means of rod bracket.

Work piece holding fixture is mounted on slide assembly. When there is longitudinal movement of top slide by means of hydraulic cylinder; work piece passes the rotating cutters and hence milling operation is performed. Stroke of this slide can be adjusted by means of limit switch and trip dogs. Trip rail is fitted to top slide and three trip dogs are mounted on it. One trip dog is for detecting home position of slide and other two trip dogs are for detecting two extreme limit positions of slide. Limit switch give signals to direction control solenoid valve of hydraulic system and hence direction and stroke of slide is adjusted as per requirement. Control and synchronization of hydraulic cylinder is achieved by configuring it in PLC program.

\subsection{FIXTURE ASSEMBLY}

Exploded three dimensional view of fixture assembly is shown in figure 5. This assembly is designed to hold the work piece rigidly by use of hydraulic power while performing milling operation.

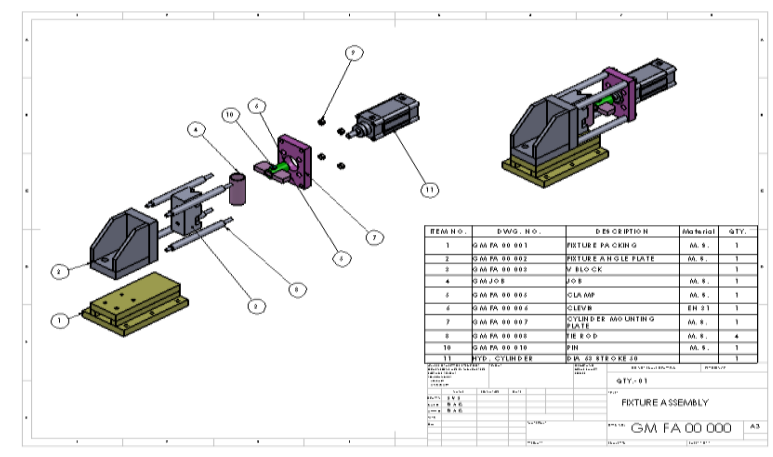

Figure 5: Fixture assembly

Fixture packing is fabricated from mild steel material and top and bottom faces of it are grinded to get dimensional accuracy and maintain parallelism. Fixture angle plate is mounted on packing and V block is fitted on its face. Faces of fixture angle plate are ground to maintain perpendicularity; so that work piece should hold exactly at right angle to achieve machining accuracy. Cylinder mounting plate is assembled with fixture angle plate by using four tie rods. Hydraulic cylinder is fitted on cylinder mounting plate and on piston rod threading clevis is screwed. Clamp is assembled with clevis by inserting pin in hole.

Work piece to be machined is held on V block and clamped rigidly in position by clamp force. To machine work piece accurately it should not move while machining; for the same reason hydraulic power is used. Control and synchronization of hydraulic cylinder is achieved by configuring it in PLC program. Flow chart for sequence of operations on the component is shown below.

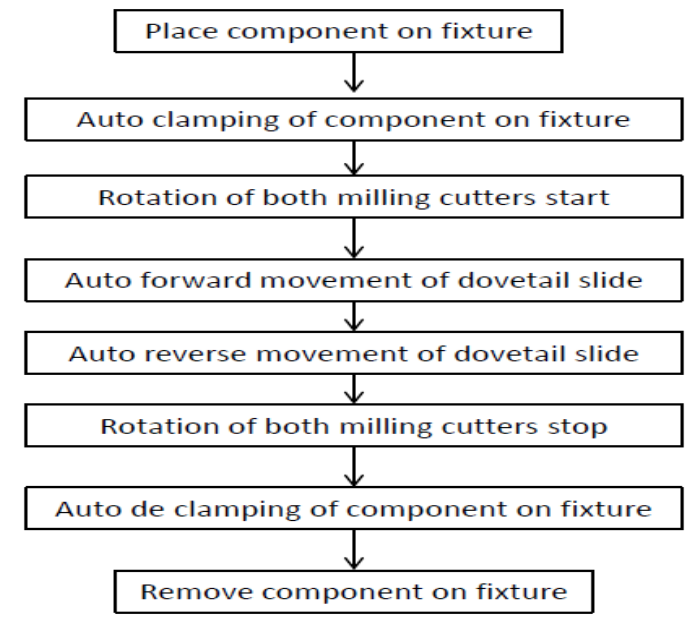




\section{CASE STUDIES}

After performance trails following observations are noted -

3.1 Reduction in cycle time

By using conventional method cycle time required to manufacture single bush is 57 seconds where as cycle time required to manufacture single bush with SPM is 27 seconds. Hence cycle time is reduced by 30 seconds.

3.2 Quantitative productivity improvement

After studying production data it is observed that number of bushes produced per shift using conventional manufacturing method are 347 numbers and by using SPM 866 numbers. Hence increase in production per shift by 519 numbers of jobs. Hence production rate improvement by 2.5 times is achieved.

3.3 Improved repeatability and accuracy

Intensive care in design and manufacturing of machine to achieve highest machining quality of bushes to be produced on machine, results in improved repeatability and accuracy in bush production. In conventional method bush was manufactured in two setups; hence quality problems were arise due to uneven conditions of two setups. On new developed machine all four flat milling operations are performed in a single setup which resolved the problem due to setup change. In standard manufacturing conditions $96 \%$ accuracy is achieved.

3.4 Less human intervention

Drastic reduction in work load is attained through the automation process which directly helps in less operator fatigue. This reduces labor cost. Daily wages of machine operator is considered 600 rupees. Then labor cost for production of each job by conventional manufacturing method is $1.73 \mathrm{Rs} / \mathrm{job}$ and by using SPM $=0.69 \mathrm{Rs} / \mathrm{job}$. Hence labor cost is reduced by $1.04 \mathrm{Rs} / \mathrm{job}$. As machine is completely automated it can be operated by semiskilled labor having less daily wages and hence it is possible to achieve again more reduction in labor cost. Skilled operator is required only for machine setting. This also solves problem of shortage of skilled labor. Less human intervention also contributed in workers safety.

\subsection{Economic justification of SPM}

Economical Investment in automation can be justified as shown in table 1.

\begin{tabular}{|l|l|}
\hline Saving in labor cost per job (Rs.) & 1.04 \\
\hline Total machine manufacturing cost (Rs.) & 841705 \\
\hline Numbers Jobs required to produce for amortization of machine cost & 809331 \\
\hline Numbers jobs produced per shift using machine & 866 \\
\hline Numbers Shifts required producing 809331 numbers of job & 934 \\
\hline If machine runs in two shifts daily; number of days required & 467 \\
\hline Number of months required by considering 25 days per month & 18.67 \\
\hline By considering interest rate and other costs total payback period of machine in months & 22 \\
\hline
\end{tabular}

Table 1: Economic justification of SPM

\subsection{Less rejection due to automatic controls}

Because of high accuracy and repeatability achieved due to automatic control system, rejection of bushes is reduced. This results in qualitative productivity improvement. In conventional method all job setting and machining activities were performed manually. Hence production quality was majorly dependent on operator's skill and efforts. In new method of machining all job setting and machining activities are performed by automatic controls which results in greater uniformity and conformity to quality specifications. Once machine is stetted properly, operator contribution is limited to only loading and unloading of job. Thus an automatic control is main reason for quality improvement and less rejection.

\subsection{Reduced power consumption}

In conventional method spindle motor runs continuously throughout production cycle and cycle time was also high this was resulting in excessive power consumption. In new developed machine due to automatic controls spindle motors runs only when machining operation is in process. Hence drastic reduction in power consumption is observed which contributed in reducing production cost.

\subsection{Minimisation of production cost}

Increased production rate, reduced production costs, reduced labor costs, reduced WIP, minimised the production costs.

Comparison of bush manufacturing on conventional milling machine and on SPM is shown in table number 2. 
Table 2: Comparison of bush manufacturing

\begin{tabular}{|l|l|l|}
\hline Parameters & Horizontal milling machine & SPM \\
\hline Cycle Time & 57 & 27 \\
\hline Jobs/shift & 347 & 866 \\
\hline Labor cost & 1.73 Rs/job & 0.69 Rs/job \\
\hline
\end{tabular}

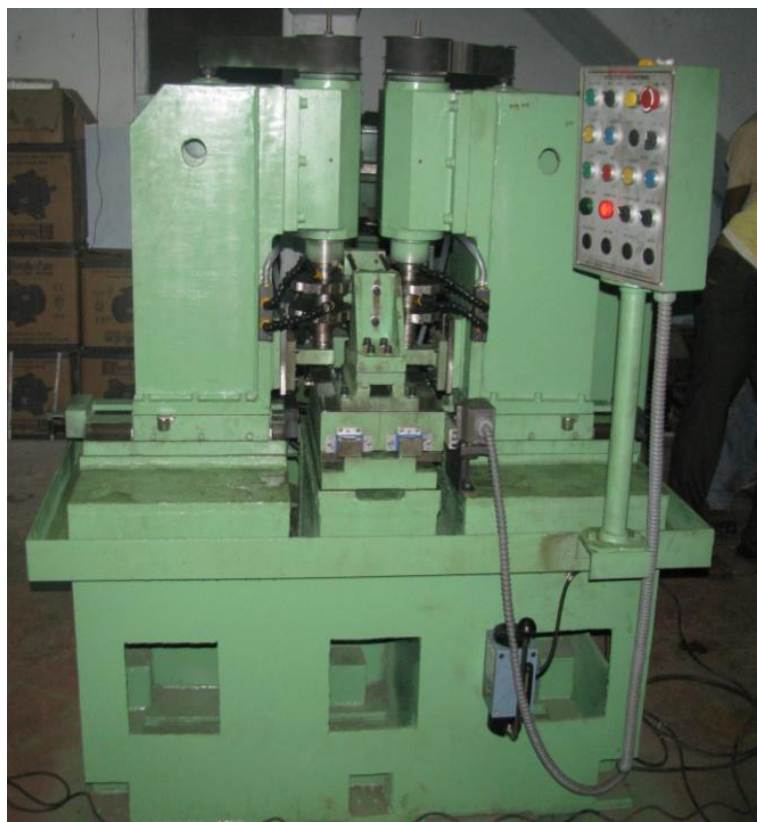

Figure 7: Photograph of new developed automation system

IV.

CONCLUSION

An effort is taken for automated manufacturing of conveyor chain bushes. Existing manufacturing process is understood, simplified and automated. New concept of automation is developed with focus on specialization of operation, simultaneous operation and increased flexibility strategies of automation. Parts are designed to meet functional requirements and also DFM and DFMA principles keeping in mind. Various twodimensional and three dimensional geometric drawings are prepared by using Solid Works CAD software. After completion of parts and subassemblies manufacturing machine is assembled and working trails of are conducted for performance analysis. Considerable improvement in productivity both qualitative and quantitative is observed with all other benefits of automation. It is concluded that new developed low cost automation is technically and economically justified and proven its effectiveness over conventional manufacturing process.

\section{REFERENCES}

[1] M. Muthukkaruppan and K. Manoj. "Low Cost Automation Using Electro-Pneumatic System-An Online Case Study In Multistation Part Transfer, Drilling And Tapping Machine”, ISARC 2007.

[2] M. Tolouei Rad. "An intelligent approach to high quantity automated machining", Journal of Achievement in material and manufacturing engineering, volume 47; issue 2; August 2011; 195-204.

[3] H. S. Dwarkanath. Low cost automation, National Productivity Council training manual.

[4] R. Neugebauer, B. Denkena , K.Wegener, "Mechatronic Systems for Machine Tools", Annals of the CIRP Manufacturing Technology, Vol.56, 2007, 657-687.

[5] Heinz-H. Erbe, "Low Cost Intelligent Automation in Manufacturing", 15th Triennial World Congress, Barcelona, Spain, 2002, IFAC.

[6] Mikell P. Groover. Automation, Production Systems, and Computer - Integrated Manufacturing, Third Edition. Prentice-Hall (2008); ISBN-978-81-203-3418-2; 15-18.

[7] Patel C H, Mohan Kumar G C, Vishwas Puttige, "Low Cost Automation For CNC Machining Center" International Journal Of Mechanical Engineering And Technology, Volume 3, Issue 2, May-August (2012), pp. 806-816, ISSN 0976 - 6340 (Print)

[8] Machine tool design handbook, Central Machine Tool Institute. Bangalore; Tata McGraw Hill Education Private Ltd, New Delhi; 32 nd reprint 2010; ISBN-13:978-0-07-451564-8. 